\title{
TINGKAT KEMATANGAN KELAMIN DAN FREKUENSI PANJANG PARI GITAR (Rhinobatus sp.1 dan Rhinobatus sp. 2)
}

\author{
Dharmadi" dan Fahmi"' \\ "Peneliti pada Pusat Riset Perikanan Tangkap, Ancol-Jakarta \\ " Peneliti pada Pusat Penelitian Oseanologi, Lembaga IImu Pengetahuan Indonesia, Ancol-Jakarta
}

\begin{abstract}
ABSTRAK
Pari gitar (Rhinobatus sp.) merupakan salah satu jenis pari yang mempunyai nilai ekonomis tinggi. Jenis pari ini sering tertangkap dengan alat tangkap jaring dasar, karena mereka hidup di dasar perairan yang berpasir. Penentuan kematangan jenis kelamin jantan dapat diketahui berdasarkan pada kondisi klasper, yang dikelompokan menjadi 3 tingkatan yaitu 1) klasper dalam kondisi lunak belum atau sedikit berisi zat kapur; 2) klasper berisi zat kapur dalam kondisi agak keras; dan 3) klasper berisi penuh zat kapur dalam kondisi keras. Ukuran panjang klasper berhubungan secara linier terhadap panjang tubuh pari gitar. Sedangkan frekuensi panjang pari gitar berfluktuasi berdasarkan pada waktu dan jenis kelamin.
\end{abstract}

KATA KUNCI: aspek biologi, pari gitar, Rhinobatus sp.

\section{PENDAHULUAN}

Pari gitar (Rhinobatus sp.) atau lebih dikenal oleh nelayan di Jawa Tengah dengan sebutan pari lionbun atau pari kekeh, merupakan satu dari beberapa jenis pari yang mempunyai nilai ekonomis tinggi terutama siripnya. Sebagai gambaran harga sirip kering jenis pari tersebut di daerah Bali pada tahun 2003 untuk kategori kelas super yang memiliki ukuran panjang sirip $40 \mathrm{~cm}$ berkisar antara 1,6 sampai dengan 2 juta rupiah per $\mathrm{kg}$, sedangkan harga terendah untuk kategori kelas plan berukuran panjang sirip antara 12 sampai dengan $15 \mathrm{~cm}$ dengan harga antara 200 sampai dengan 400 ribu rupiah per $\mathrm{kg}$ (Komunikasi pribadi dengan pedagang pengumpul sirip cucut). Harga sirip jenis pari ini lebih tinggi dibanding dengan harga sirip jenis cucut lainnya. Ikan pari gitar tersebar di perairan pantai yang beriklim sedang dan panas yang sampai saat ini diketahui berjumlah 45 jenis (Manik, 2003). Dalam klasifikasi ikan, Rhinobatus merupakan salah satu genus dari subfamili Rhinobatinae, famili Rhinobatidae, dan ordo Rajiformes (Nelson, 1976).

Klasper sebagai alat kelamin pada jenis jantan jumlahnya 2 pasang yaitu di bagian kanan dan kiri terletak pada perut bagian belakang, memanjang ke arah sirip ekor dari bagian tengah pada masingmasing sirip perut. Menurut Wenbin \& Shuyuan (1993) pada pari jantan yang matang, posisi klasper berada di bawah pinggir ke arah depan dari sirip perut. Klasper mempunyai pigmen yang sama dengan tubuh. Bagian permukaan punggung klasper berwarna abu-abu dan pada permukaan perutnya berwarna putih.

Hasil pengamatan mengemukakan, tempat penangkapan ikan Kedonganan, Bali merupakan salah satu daerah di mana nelayan lokal banyak yang melakukan penangkapan pari kekeh. Jenis pari ini lebih sering tertangkap dengan jaring udang karena habitat mereka adalah di dasar perairan. Informasi tentang aspek biologi pari gitar sampai dengan saat ini relatif sangat terbatas, karena itu tulisan ini merupakan informasi dasar dalam mempelajari aspek biologi reproduksi ikan pari gitar.

\section{PENENTUAN KEMATANGAN JENIS KELAMIN JANTAN}

Berdasarkan pada kondisi klasper, pari gitar dikelompokan menjadi 3 tingkat kematangan kelamin yaitu a) klasper belum matang di mana klasper dalam kondisi lunak belum atau sedikit berisi zat kapur dan berukuran lebih kecil (not calcification); b) klasper berukuran sedang berisi sebagian zat kapur dan dalam kondisi agak keras (not full calcification); dan c) klasper berukuran besar berisi penuh zat kapur dan dalam kondisi mengeras (full calcification)

Pada pari kekeh (Rhinobatus sp.1) (Gambar 1) ditandai dengan terdapatnya bintik-bintik putih pada tubuh bagian dorsal, sedangkan pari Rhinobatus sp.2 (Gambar 2) pada tubuhnya terdapat benjolanbenjolan kecil seperti jerawat, tidak terdapat bintikbintik putih pada bagian dorsal dan memiliki hidung lebih panjang. Secara morfologi, bentuk tubuh ke-2 spesies tersebut relatif sama.

\section{HUBUNGAN ANTARA PANJANG TUBUH DAN PANJANG KLASPER}

Hubungan antara panjang total tubuh dan panjang klasper pari kekeh berdasarkan pada tingkatan kematangan kelamin dikelompokan menjadi 3 tingkatan. Pada klasper yang muda atau dalam kondisi belum terjadi pengapuran mempunyai panjang antara 18 sampai dengan $35 \mathrm{~mm}$ dengan panjang total tubuh antara 542 sampai dengan $682 \mathrm{~mm}$ (Gambar 3a). Pada klasper yang telah berisi sebagian 


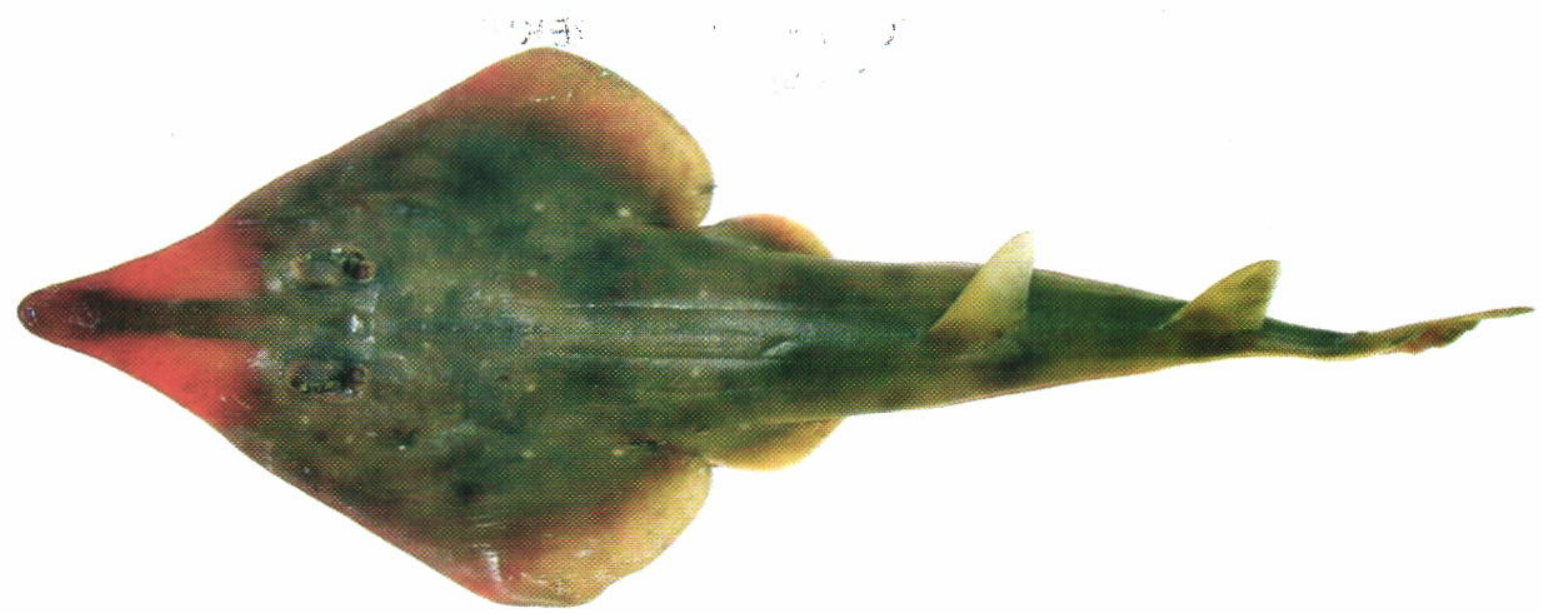

Gambar 1. Rhinobatus sp.1.

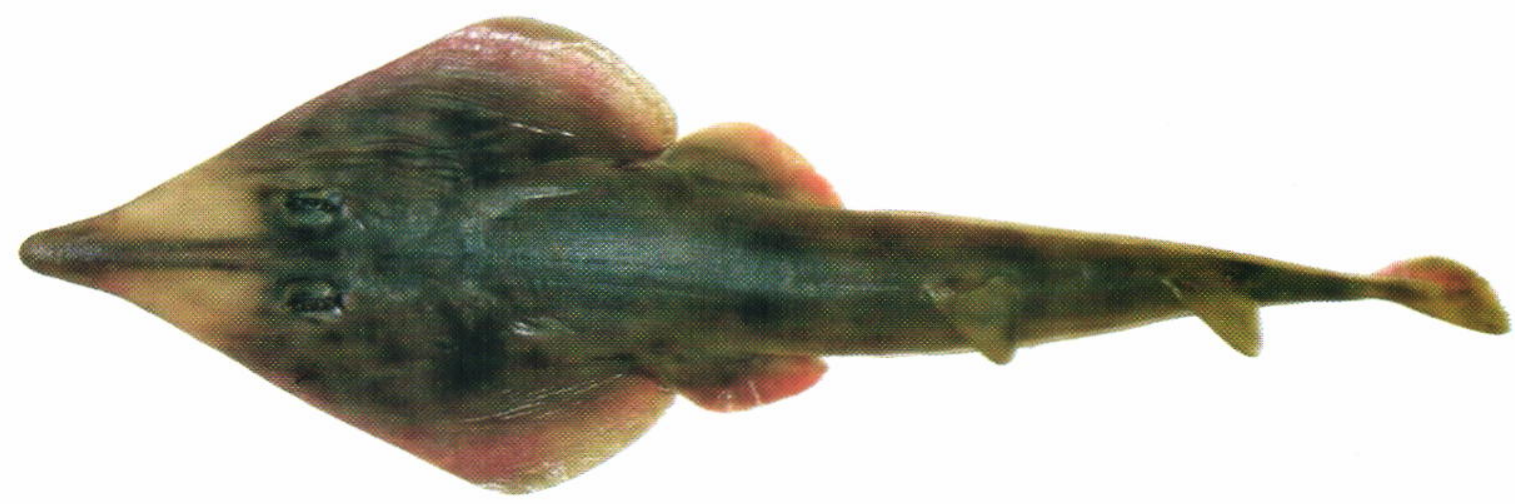

Gambar 2. Rhinobatus sp.2.

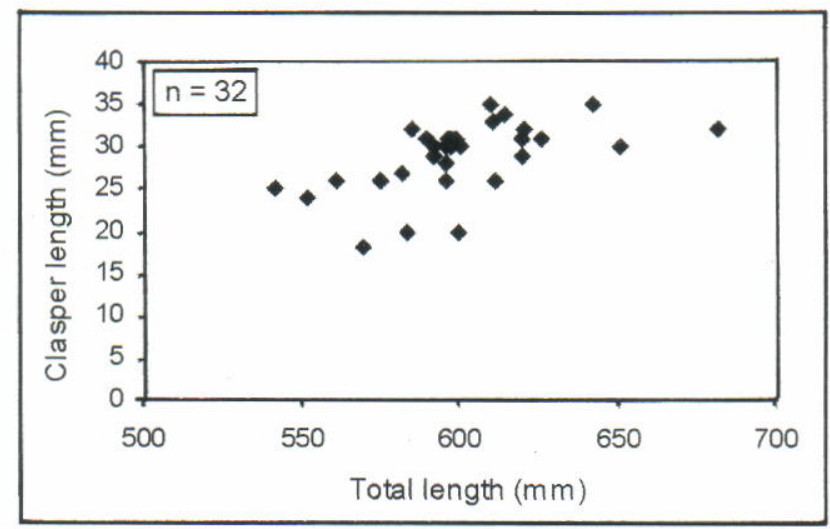

Gambar 3a. Hubungan antara panjang total dan panjang klasper yang belum mengalami pengapuran.

zat kapur atau not full calcification terdapat pada ukuran panjang antara 32 sampai dengan $55 \mathrm{~mm}$ dengan panjang total tubuh antara 610 sampai dengan $740 \mathrm{~mm}$ (Gambar 3b), sedangkan klasper yang sudah dipenuhi zat kapur dan dalam kondisi mengeras mempunyai panjang antara 47 sampai dengan $57 \mathrm{~mm}$ dengan panjang total tubuh antara 672 sampai dengan 855 mm (Gambar 3c).

\section{FREKUENSI PANJANG}

Frekuensi panjang total ikan pari kekeh berdasarkan pada waktu pengamatan disajikan pada Gambar 4. Menurut Compagno (1984) genus Rhinobatus berukuran lebih kecil seperti cucut genus batoid dan ukuran dewasa mempunyai panjang total antara 500 sampai dengan $1.500 \mathrm{~mm}$. Pengamatan 


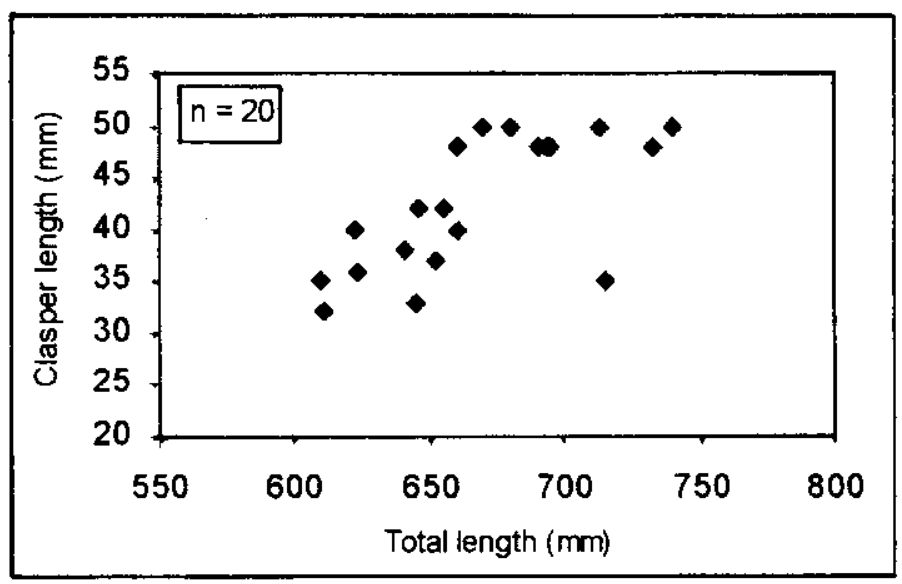

Gambar 3b. Hubungan antara panjang total dan panjang klasper yang mengalami pengapuran sebagian.

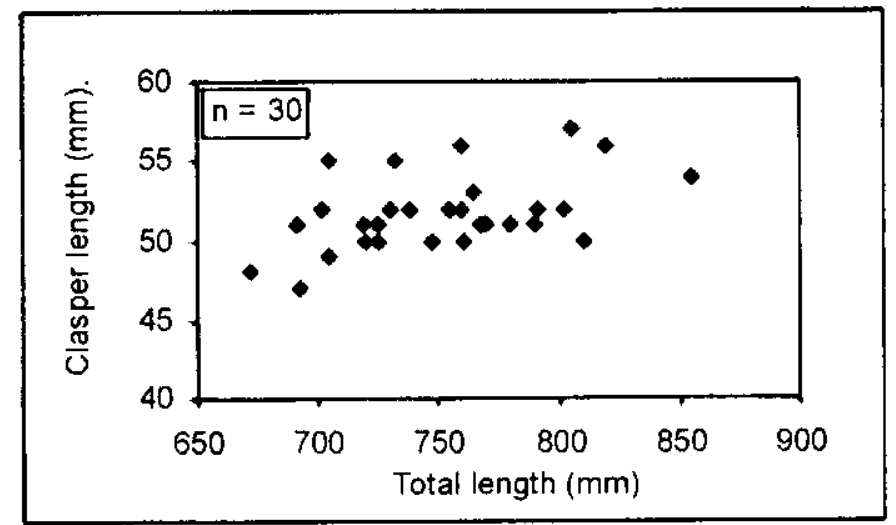

Gambar 3c. Hubungan antara panjang total dan panjang klasper yang mengalami pengapuran penuh.

pada bulan Mei sampai dengan Juni 2004 di tempat penangkapan ikan Kedonganan, Bali menunjukkan hasil tangkapan didominasi oleh pari kekeh betina dengan frekuensi panjang terendah pada ukuran kelas panjang antara 410 sampai dengan $500 \mathrm{~mm}$ dan tertinggi pada ukuran kelas panjang antara 810 sampai dengan $900 \mathrm{~mm}$. Pada bulan Agustus sampai dengan Oktober 2002 hasil tangkapan didominasi oleh pari kekeh jantan dengan panjang terendah pada kisaran antara 910 sampai dengan $1.000 \mathrm{~mm}$ dan tertinggi pada kisaran antara 510 sampai dengan 600 $\mathrm{mm}$.

Pari kekeh (Rhinobatus sp.1) banyak didaratkan di PPI Pelabuhan Ratu, PPN Cilacap, TPI Kedonganan, dan PPI Tanjung Luar, tetapi di TPI Kedonganan lebih banyak ditemukan dibandingkan dengan tempat pendaratan ikan lainnya. Pari kekeh jantan yang tertangkap berukuran antara 561 sampai dengan 774 $\mathrm{mm}$, dan betina antara 529 sampai dengan $92,1 \mathrm{~mm}$ Pada bulan Maret sampai dengan Juni jumlah pari kekeh betina yang tertangkap lebih banyak dibanding pari kekeh jantan, tetapi sebaliknya pada bulan Agustus sampai dengan Oktober jumlah jenis jantan lebih banyak daripada jenis betina. Pari kekeh (Rhinobatus sp.2) juga sering dijumpai di tempat penangkapan ikan Kedonganan, meskipun kadangkadang ditemukan di tempat penangkapan ikan Muara Angke. Pari kekeh jantan berukuran antara 568 sampai dengan $855 \mathrm{~mm}$ dan betina berukuran antara 572 sampai dengan $903 \mathrm{~mm}$. Untuk mempelajari musim penangkapan pari kekeh yang tepat diperlukan analisis data hasil tangkapan yang runtun selama beberapa tahun. 
(a) Rhinobatus sp. 1
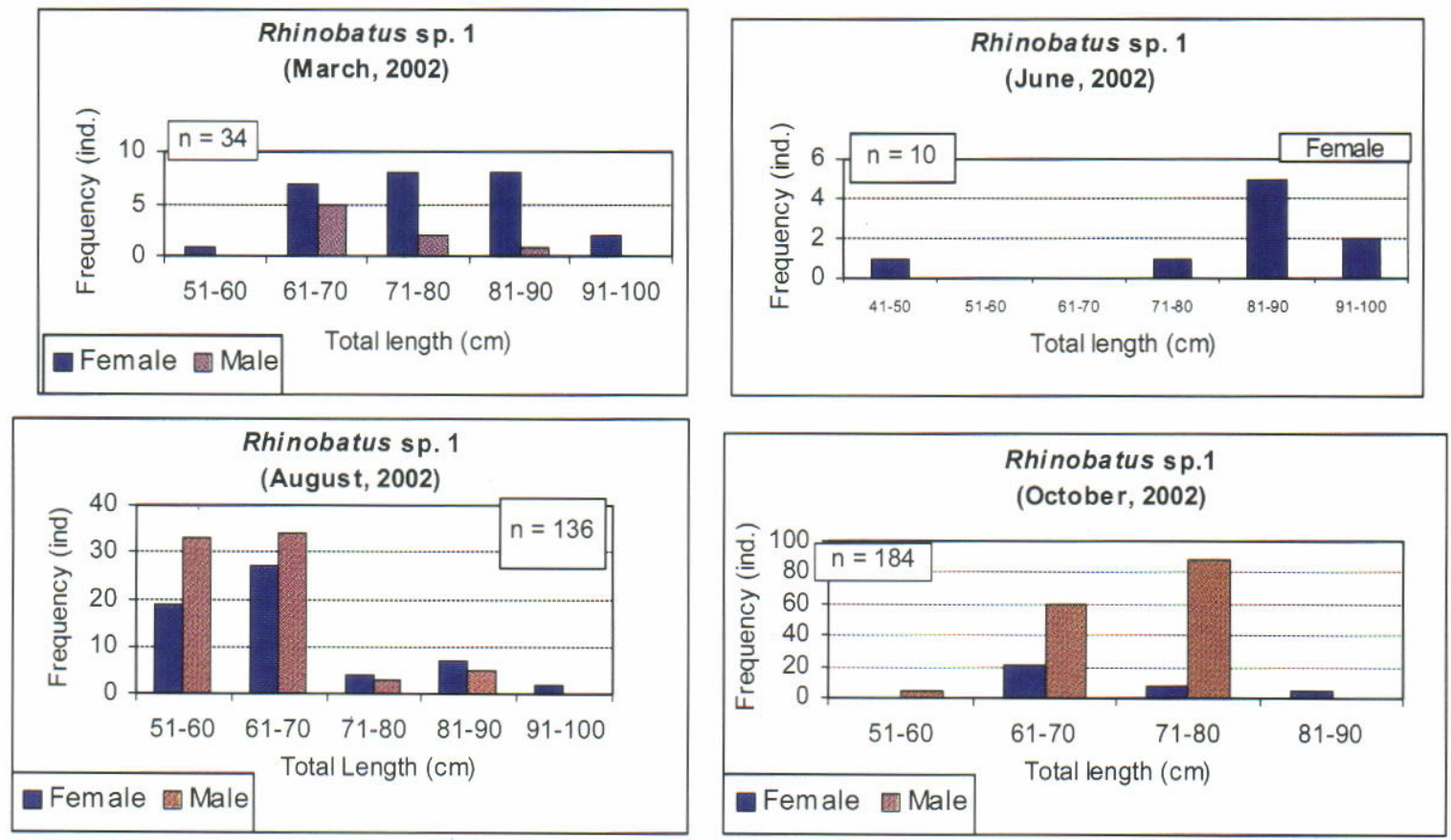

(b) Rhinobatus sp. 2

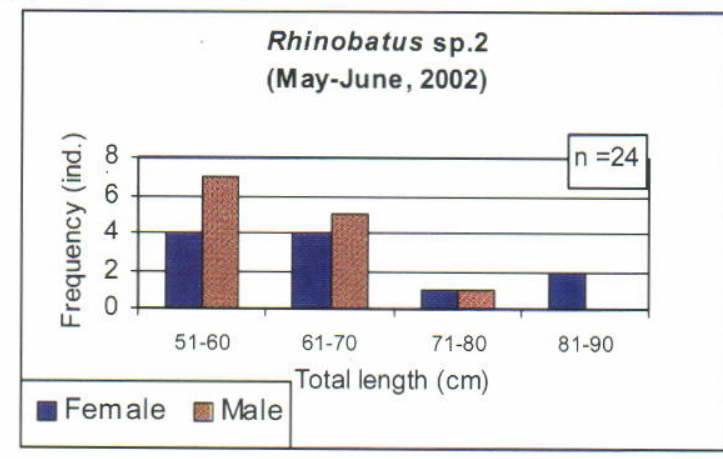

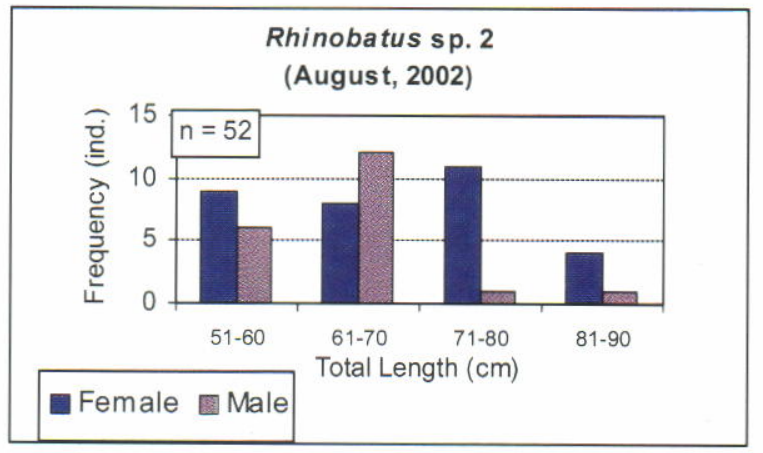

Female male

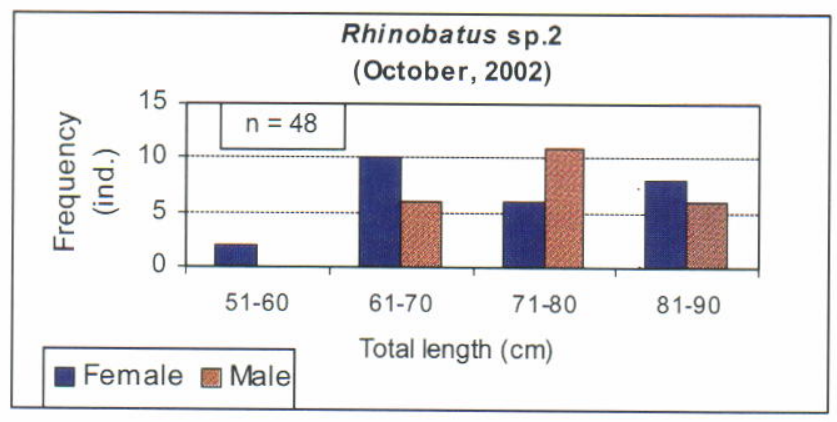

Gambar 4. Frekuensi panjang total i Rhinobatus sp.1 (a) dan Rhinobatus sp.2 (b) yang didaratkan di tempat penangkapan ikan Kedonganan Bali, bulan Maret sampai dengan Oktober 2002. 


\section{KESIMPULAN}

1. Tingkat kematangan kelamin jantan pari gitar atau pari kekeh ditentukan oleh kondisi klasper. Semakin panjang dan semakin keras kondisi klasper menunjukkan bahwa pari tersebut telah siap untuk memijah.

2. Frekuensi panjang pari kekeh berfluktuatif berdasarkan pada waktu dan jenis kelaminnya.

\section{DAFTAR PUSTAKA}

Compagno, L. J. V. 1984. FAO species catalogue. Vol.4. Sharks of the world. An annotated and illustrated catalogue of sharks species known to date. Part 1. Hexanchiformes to Lamniformes.
FAO Fish. Synop. (125) Vol. 4. Pt 1: 249 p.

Manik, N. 2003. Beberapa catatan mengenai ikan pari. Oseana. Vol.XXVIII No.4, 2003: 17-23. Majalah Ilimiah Semi Populer. Pusat Penelitian Oseanologi. Lembaga IImu Pengetahuan Indonesia.

Nelson, J. S. 1976. Fishes of the world. Jhon Wiley \& Sons. Inc. Canada: $416 \mathrm{p}$.

Wenbin, Z. \& Q. Shuyun. 1993. Reproductive biology of the guitarfish, Rhinobatos hynnicephalus. Environmental Biology of Fishes. Department of Oceanographiy. Xiamen University. Xiamen Fujian. P. R. of China. Kluwer Academic Publishers. 38: 81-93. 1993. 
